\title{
Describing associations between child maltreatment frequency and the frequency and timing of subsequent delinquent or criminal behaviors across development: variation by sex, sexual orientation, and race
}

\author{
Hannah Lantos ${ }^{1,2^{*}}$ (D) Andra Wilkinson ${ }^{1,3}$, Hannah Winslow ${ }^{1}$ and Tyler McDaniel ${ }^{1,4}$
}

\begin{abstract}
Background: Child maltreatment has been linked to lower health, education, and income later in life, and is associated with increased engagement in delinquent or criminal behaviors. This paper explores trajectories of these behaviors from adolescence into early adulthood and tests maltreatment as a predictor, and whether observed patterns are consistent across different demographic groups.

Methods: Using data from the National Longitudinal Study of Adolescent to Adult Health, a longitudinal study of a nationally representative sample of U.S. adolescents (in grades 7-12 in the 1994-95 school year), we ran linear mixed effects models to estimate growth curves of two dependent variables: violent and nonviolent offending behavior. We tested if maltreatment altered the intercept or slope of the curves and how the curves of these behaviors and the associations between them and maltreatment varied by sex, race/ethnicity, and sexual orientation.

Results: The sample $(n=10,613)$ had equal proportions males and females, approximately one third identified as a race/ethnicity other than white, and over 10\% were non-heterosexual. Experiences of maltreatment were highest for Native Americans and lowest for whites. Models indicated that males were more likely than females to engage in both violent and nonviolent offending and respondents who identified as non-heterosexual were more likely than their heterosexual peers to engage in nonviolent offending behavior. When maltreatment was included in models as a predictor, adolescents who experienced maltreatment had a more rapid increase in their non-violent offending behavior. For violent offending behavior, adolescents who experienced maltreatment had higher levels of offending and the levels progressively increased as maltreatment frequency did. Sex was a moderator; the relationship between maltreatment and predicted nonviolent offending was stronger for males than it was for females. Race/ethnicity and sexual orientation did not moderate the associations between maltreatment and offending behavior.

* Correspondence: hlantos@childtrends.org

${ }^{1}$ Child Trends, 7315 Wisconsin Ave, Suite 1200W, Bethesda, MD 20814, USA

2Department of Population, Family, and Reproductive Health, Johns Hopkins

Bloomberg School of Public Health, 615 N. Wolfe St, Baltimore, MD 21205,

USA

Full list of author information is available at the end of the article

(c) The Author(s). 2019 Open Access This article is distributed under the terms of the Creative Commons Attribution 4.0 International License (http://creativecommons.org/licenses/by/4.0/), which permits unrestricted use, distribution, and reproduction in any medium, provided you give appropriate credit to the original author(s) and the source, provide a link to the Creative Commons license, and indicate if changes were made. The Creative Commons Public Domain Dedication waiver (http://creativecommons.org/publicdomain/zero/1.0/) applies to the data made available in this article, unless otherwise stated. 
(Continued from previous page)

Conclusions: This study provides insights from a nationally representative sample into the pattern of both delinquent and criminal behaviors in adolescence and young adulthood, describing not only how the pattern varies over time, but also by sociodemographics and offending type. Additionally, it highlights how the association between maltreatment and these behaviors varies by both offending type and sex.

Keywords: Maltreatment, Abuse, Delinquency, Violent, Nonviolent,

\section{Background}

The most recent data on child maltreatment in the United States indicates that 9.1 out of 1000 children have experienced maltreatment that resulted in their involvement in the child welfare system [1]. Federal data collection efforts in the United States track multiple types of maltreatment over time - defined as abuse (including physical, sexual, emotional, or psychological), exploitation, or neglect perpetrated by someone who has power over a child (e.g., a parent, teacher, clergy member, or other caregiver) [2]. Neglect is by far the most common type of maltreatment experienced among those children tracked by the federal government. Just over three-quarters of children who have been maltreated have experienced neglect while nearly one in five (18\%) cases report physical abuse and nearly one in ten (9\%) report sexual abuse. Other types of maltreatment such as emotional abuse, a parent's substance abuse, or a lack of supervision were experienced by nearly $11 \%$ of the children. As the percentages show (by adding up to more than 100), many children experience multiple types of maltreatment (14\%), with the most common combination being physical abuse and neglect (5\%) [3].

While the immediate effects of maltreatment are clear, there are many ways that maltreatment continues to affect children's well-being. Maltreatment and experiences of violence impact children's well-being long into the future - affecting their physical and emotional health [4-6], school attainment [7], and socioeconomic stability [8] into adulthood. Additionally, there is risk of a link between experiences of maltreatment and engagement in delinquent behaviors during childhood and adolescence [9]. Children who are exposed to maltreatment are more likely to engage in delinquent behavior later, such as stealing or committing violence [10]. A study of a nationally representative group of 14-year-olds found that an adolescent may be 40-60\% more likely to engage in delinquent behavior if they were maltreated as a child [11]. Additionally, among justice-involved youth - youth who have been caught and convicted of criminal delinquency $-40-90 \%$ of girls and $25-65 \%$ of boys are estimated to have experienced maltreatment in childhood [12]. Note that we use the terms "delinquent or criminal behavior" as well as "offending behavior" or "offenses" in this paper. This is because delinquent behavior refers to youth under the age of 18 while for adults, these behaviors are often criminal offenses. Thus, these terms are used throughout the paper to capture the changes in behavior across ages.

Notably, there are two questions embedded in these statistics that are different in important ways: 1) of the kids who experienced maltreatment, how many (and who) will go on to engage in delinquent or criminal behavior versus 2) of those who have engaged in delinquent or criminal behavior, how many experienced maltreatment? There is a long record of scholarship focused on these questions with papers using data from both larger studies as well as from small, homogenous, high-risk samples. For example, one study found relationships between maltreatment and violent delinquency and studied variation in these associations driven by different types of maltreatment [13] while a second one looked at the developmental processes underlying "aging out" of crime [14]. Another one looked specifically at the immediate and long-term associations between violence exposure and delinquent behavior finding longterm associations that are attenuated over time [15].

In this paper, we focus on the first question because our data enable us to explore these questions in the general population. Using this large, nationally representative sample, we are able to stratify by multiple races as well as by sexuality - sub-samples which are often too small in other samples. We also are able to study the specific timing of the delinquent behavior across a young person's life by modeling growth curves across ages. This is possible in our study because respondents were not all the same age in Wave $\mathrm{I}$, meaning we are able to include respondents of all ages from ages 12 to 30 .

The present study uses longitudinal data from a large nationally representative study of adolescents who were followed into young adulthood. As the data source included not only multiple types of maltreatment and delinquent and criminal behaviors, but also their frequency, the present study was able to use linear mixed effects models to examine the relationship between maltreatment and these behaviors across ages. The two research questions and hypotheses we proposed were as follows:

1. What is the relationship between childhood maltreatment and delinquent or criminal behaviors from adolescence into young adulthood? 
Hypothesis: Increased frequency of maltreatment experiences will be associated with a higher frequency of non-violent and violent offending frequency across development than the pattern observed for youth who did not experience childhood maltreatment [16-20].

2. Does this relationship vary by sex, race/ethnicity, and sexual orientation and if so, how?

Hypothesis: The positive association between maltreatment frequency and delinquency frequency to be moderated by sex, race/ethnicity, and sexual orientation such that the association would be stronger for females, youth of color, and LGBTQI youth compared to their male, white, or straight peers [16, 21-23].

Our use of the robust method of linear mixed effects models allowed exploration of these trajectories and how they differ by race, sex, and sexual orientation. Additionally, while using self-reported versus administrative data on experiences of maltreatment both have their strengths and weaknesses [24], this paper uses selfreported data for both reports of maltreatment and delinquent behavior. The data come from a large, wellknown, nationally representative, longitudinal sample and allow us to explore these associations.

\section{Methods}

\section{Sample}

The present study used data from the National Longitudinal Study of Adolescent to Adult Health (Add Health), a longitudinal study of a nationally representative sample of U.S. adolescents who were in grades 7-12 in the 1994-95 school year (Wave I, adolescence). There have been four in-home interviews to date. The sample used in these analyses was restricted to respondents interviewed at Waves I, III (ages 18 to 26, emerging adulthood), and IV (ages 24 to 32, young adulthood), with valid sampling weights $(N=12,288)$ and who had complete data on all variables of interest $(N=10,613$, $86 \%)$. Data from Wave II were not used as Wave I high school seniors were not followed by design. Details of the Add Health study and design are described elsewhere [25]. Our secondary analyses were reviewed by the Institutional Review Board at Child Trends and deemed exempt.

\section{Measures \\ Independent variable: childhood maltreatment frequency}

Childhood maltreatment was measured via a categorical variable capturing frequency (0 [never] - 10 [10 or more times]) of experiencing emotional, physical, or sexual abuse before age 18 or physical or supervisory neglect before sixth grade by a parent or an adult caregiver. This variable captures frequency of maltreatment rather than type because recent evidence suggests the chronicity of maltreatment is potentially a better indicator of negative consequences than the type of maltreatment (severity is not measured in Add Health) [26]. The average maltreatment frequency in our analytic sample was 2.6 times with a standard deviation of 2.7.

\section{Dependent variable: frequency of delinquent and criminal offenses}

Offense frequency was measured at each wave via two scales of frequency in the past 12 months, one for both violent and nonviolent offenses, mirroring prior measures of offenses using Add Health data [27, 28]. Violent offense frequency (alpha $=.60-.73$, across the waves) included the following indicators at each wave: shooting or stabbing someone; hurting someone badly enough to need bandages or care from a doctor or nurse; using or threatening a weapon to get something from someone; pulling a knife or gun on someone; and being in a group fight. In adolescence (Wave I), the mean frequency of committing violent offenses in the past year was 0.72 (or less than one average violent offense per year), and by young adulthood (Wave IV), the mean frequency dropped to 0.19 .

Nonviolent offense frequency (alpha $=.50-.66$, across the waves) included the following indicators at each wave: deliberately damaging property that didn't belong to you; going into a house or building to steal something; stealing something worth less than $\$ 50$; stealing something worth more than $\$ 50$; selling marijuana or other drugs; and taking an illegal drug using a needle. The choice of indicators was constrained by what items were included in the survey, which were included in each Wave; and if items fit better conceptually as control variables. In adolescence, the mean frequency of nonviolent offenses in the past year was 0.86 and this dropped to 0.25 by young adulthood.

\section{Control variables}

Previously published relevant analyses were reviewed to inform the type of potential confounders that should be controlled for [29-31]. Sociodemographic variables included sex and race/ethnicity from Wave I (Hispanic and non-Hispanic White, Black, Asian, Native American, and Other), and sexual orientation/attraction (respondent included if they identified as homosexual or bisexual or if they reported attraction to the same sex) at Wave III. Trouble in school was measured with an indicator of whether the respondent had ever repeated or been held back a grade and another indicator if they had ever been suspended, expelled, or dropped out. An indicator of whether anyone in the household had received public assistance before the respondent was 18-years-old was used to approximate the socioeconomic status of their 
childhood home. Whether the respondent had ever lived in a foster home was also included. Finally, any use of substances before Wave I was controlled for, including alcohol, cigarettes, marijuana, and other illicit substances. Injection drug use was not included in this measure as it was included in the nonviolent offense frequency measure.

\section{Analyses}

The data set was structured by age instead of wave to capture the developmental trajectory from adolescence to young adulthood. Linear mixed effects models were used to estimate growth curves of the two dependent variables: frequency of either violent or nonviolent delinquent or criminal behaviors. These models allowed for estimation of change over time while controlling for unobserved time-invariant characteristics that could confound any associations. Nine models were fit for each of the two dependent variables. The first five models were used to estimate patterns of offenses starting with an unadjusted model, adding covariates, and testing moderation of the base pattern of offenses by sex, race/ ethnicity and sexual orientation. The next four models test a temporal association, whether childhood maltreatment is significantly associated with the starting point and trend in the growth curve of offenses, and whether the association varies by sex, race/ethnicity, or sexual orientation.

All significant models were run with a random intercept and slope to examine variation in the effect. The intraclass correlation coefficient (ICC), used in linear mixed effects models to determine the percentage of variance in offense frequency that is due to variance between individuals was used in these analyses. However, the sampling weights for analyzing the Add Health data inhibit testing if the ICC is significantly different than zero. So, the ICC from the first and the last model were compared to determine how much of the variance in offense frequency was explained by the predictor variables.

\section{Results}

The analytic sample (Table 1) was comprised of equal proportions of males and females. Approximately onethird of the sample were young people of color. Over $10 \%$ of the sample reported sexual attraction to either both sexes or the same sex and/or reported their sexual orientation as something other than $100 \%$ heterosexual. The majority of the sample (77.0\%) had experienced at least one type of maltreatment in childhood. Nearly onethird $(32.5 \%)$ of the sample had committed nonviolent offenses and $30 \%$ had committed violent offenses during their adolescence (Wave I).
The key predictor and outcome variables showed variation by sociodemographic characteristics (Table 2). The average childhood maltreatment frequency was highest for Native Americans and lowest for Whites in adolescence ( $M=3.56$ vs. 2.54 , respectively). Average nonviolent delinquency frequency in adolescence was higher for Lesbian, Gay, Bisexual or Queer (LGBQ) youth compared to their non-LGBQ counterparts $(M=1.10$ vs. 0.82). For violent delinquency, average frequency in adolescence was again highest for Native Americans and lowest for Whites $(\mathrm{M}=1.26$ vs. 0.57). Average frequency of both nonviolent and violent delinquency was higher for males compared to females during adolescence.

The results of our analyses can be broken down into two main parts: in the first, we studied the pattern of delinquent and criminal behavior by age; in the second, we studied the relationship between maltreatment and these behaviors. In the first part, we found that the trend in the frequency of these behaviors declines steadily from adolescence into young adulthood. When examining variation in offending frequency by sociodemographic variables, there appears to be a significant difference by sex, with males having consistently higher predicted offending frequencies than females across development, for both violent (Fig. 1a) and nonviolent offending (Fig. 1b) (Additional file 1: Table S1 and Additional file 2: Table $\mathrm{S} 2$ show the model results in table form and Additional file 3: Table S3 shows the intraclass correlation for both violent and nonviolent offending models comparing baseline and analytic models).

For other sociodemographic categories, we found evidence of significant moderation by sexual orientation such that individuals identifying as LGBQ had significantly higher predicted nonviolent offending frequency across development compared to non-LGBQ individuals (Fig. 2).

In the remaining tests for moderation by sociodemographics (race/ethnicity), the results, though statistically significant, were not robust enough to be shared. For example, there were only statistically significant differences in the tails of the graphs and thus the images make the differences look more robust than they likely are.

In the second part of our analyses, we examined the association between childhood maltreatment and nonviolent and violent delinquent and criminal offending frequency across age. Specifically, our results focus on whether the level or rate of change differed across maltreatment status. Figures $3 \mathrm{a}$ and $\mathrm{b}$ below demonstrate that maltreatment significantly alters the pattern of predicted offending frequency across age. For violent offending (Fig. 3a), any maltreatment moderates the relationships such that increased frequency of maltreatment is associated with more delinquent behavior. For example, those who experienced maltreatment start one whole instance of predicted violent delinquency higher in early adolescence; moreover, the gap 
Table 1 Demographic summary of analytic sample, including total Ns and sample percentages by category

\begin{tabular}{|c|c|c|}
\hline & $\mathrm{N}$ or mean & Weighted $\%$ or SD \\
\hline \multicolumn{3}{|l|}{ Sex } \\
\hline Male & 5373 & $50.6 \%$ \\
\hline Female & 5240 & $49.4 \%$ \\
\hline \multicolumn{3}{|l|}{ Race/ethnicity } \\
\hline Hispanic & 1249 & $11.8 \%$ \\
\hline Black & 1600 & $15.1 \%$ \\
\hline Asian & 375 & $3.5 \%$ \\
\hline American & 217 & $2.0 \%$ \\
\hline Other & 102 & $1.0 \%$ \\
\hline White & 7070 & $66.6 \%$ \\
\hline \multicolumn{3}{|l|}{ Sexual Orientation } \\
\hline LGBQ & 1305 & $12.3 \%$ \\
\hline Age at Wave I & 15.4 & 1.8 \\
\hline Age at Wave III & 21.8 & 1.9 \\
\hline Age at Wave IV & 28.3 & 1.9 \\
\hline \multicolumn{3}{|l|}{ Nonviolent offending (any) } \\
\hline Nonviolent offending frequency at Wave I & 3449 & $32.5 \%$ \\
\hline Nonviolent offending frequency at Wave III & 1983 & $18.7 \%$ \\
\hline Nonviolent offending frequency at Wave IV & 1145 & $10.8 \%$ \\
\hline \multicolumn{3}{|l|}{ Violent offending (any) } \\
\hline Violent offending frequency at Wave I & 3113 & $29.3 \%$ \\
\hline Violent offending frequency at Wave III & 1308 & $12.3 \%$ \\
\hline Violent offending frequency at Wave IV & 650 & $6.1 \%$ \\
\hline Maltreatment (any) & 7145 & $67.3 \%$ \\
\hline \multicolumn{3}{|l|}{ Control Variables } \\
\hline Public assistance in household before age 18 & 1673 & $15.8 \%$ \\
\hline Ever repeated or been held back a grade & 2150 & $20.3 \%$ \\
\hline Ever suspended, expelled or dropped out & 142 & $1.3 \%$ \\
\hline Ever used alcohol, cigarettes, or illicit substances & 6181 & $58.2 \%$ \\
\hline Ever in a foster home & 173 & $1.6 \%$ \\
\hline
\end{tabular}

persists into adulthood and does not appear to vary much by maltreatment frequency. For nonviolent offending (Fig. 3b), maltreatment frequency moderates the rate at which youth engage in delinquent behavior over time. For those who experienced maltreatment, the rate of change (slope) in predicted nonviolent offending frequency increases in early adolescence and peaks in the later teenage years; this increase is steeper and peaks at a higher point as maltreatment frequency goes up (solid, red line in Fig. 3b). Maltreatment frequencies of three and six were chosen for the figures as they were commonly reported frequencies by respondents.

Breaking down these relationships further, we found significant moderation by sex such that the relationship between maltreatment and predicted nonviolent offending is stronger for males compared to females. In Fig. 4, below, we see the gap between the blue lines (for males) is much larger than the gap between the dashed red lines (for females). The solid blue line peaks with teenage maltreated males having the greatest predicted nonviolent offense frequency. For violent offending, we only found evidence for moderation by sex in the absence of maltreatment.

We found no evidence suggesting that race or sexual orientation moderate the relationship between maltreatment and nonviolent or violent offense frequency. Comparing the ICCs across the respective models, we noted decreases in the ICC, indicating the predictor variables were explaining some of the variance in offending frequency. For example, the ICC baseline model for violent offending frequency (M1) indicates $16 \%$ of the variance in violent offending frequency is due to variance 
Table 2 Average maltreatment, nonviolent offense and violent offense frequency by demographic descriptors

\begin{tabular}{|c|c|c|c|c|c|c|}
\hline & \multicolumn{2}{|c|}{$\begin{array}{l}\text { Average maltreatment } \\
\text { frequency }\end{array}$} & \multicolumn{2}{|c|}{$\begin{array}{l}\text { Average nonviolent offense frequency in } \\
\text { adolescence }\end{array}$} & \multicolumn{2}{|c|}{$\begin{array}{l}\text { Average violent offense frequency in } \\
\text { adolescence }\end{array}$} \\
\hline & Mean & Std. Dev. & Mean & Std. Dev. & Mean & Std. Dev. \\
\hline \multicolumn{7}{|l|}{ Sex } \\
\hline Male & 2.51 & 2.48 & $1.13^{* * *}$ & 1.93 & $0.97^{* * *}$ & 1.87 \\
\hline Female & $2.78^{* * *}$ & 2.92 & 0.58 & 1.47 & 0.45 & 1.28 \\
\hline \multicolumn{7}{|c|}{ Race/ethnicity (white = referent) } \\
\hline Hispanic & $2.88^{* *}$ & 3.22 & $1.07^{*}$ & 2.33 & $1.13^{* * *}$ & 2.74 \\
\hline Black & 2.64 & 3.10 & $0.65^{*}$ & 1.78 & $1.01^{* * *}$ & 2.28 \\
\hline Asian & $3.31^{* * *}$ & 4.03 & 0.97 & 2.65 & 0.63 & 2.06 \\
\hline Native American & $3.56^{* * *}$ & 3.18 & $1.26^{*}$ & 2.05 & $1.26^{* * *}$ & 2.11 \\
\hline Other & 2.52 & 2.12 & 1.09 & 2.11 & 0.58 & 1.62 \\
\hline White & 2.54 & 2.40 & 0.84 & 1.58 & 0.57 & 1.24 \\
\hline \multicolumn{7}{|l|}{ LGBQ } \\
\hline No & 2.53 & 2.65 & 0.82 & 1.74 & 0.72 & 1.67 \\
\hline Yes & $3.40^{* * *}$ & 2.93 & $1.10^{* * *}$ & 1.99 & 0.67 & 1.59 \\
\hline
\end{tabular}

${ }^{*} p$-value $<0.05 ;{ }^{* *} p$-value $<0.01 ;$ and ${ }^{* * *} p$-value $<0.001$ in post hoc testing

between individuals. The predictor variables added in subsequent models reduced this to $10 \%$, meaning the bulk of the variance in violent offending is within individuals over time, rather than between them. The ICC for nonviolent offending models also decreased from 19 to $13 \%$. Random effects by intercept and slope did not add meaningful variation to any of the demonstrated models.

\section{Discussion}

Findings from this research uncovered patterns in the relationship between maltreatment and later delinquent and criminal behaviors from adolescence into young adulthood and how these patterns vary by sociodemographics. Specifically, we explored how maltreatment frequency affected the starting point and trajectory over time in predicted offense frequency from ages 12 to 30 and how this pattern varied by sex, race/ ethnicity, and sexual orientation.

To answer our first research question, we found that those youth who had experienced maltreatment were more likely to engage in violent offending behavior, a finding backed up by previous research [32-34]. We also found that youth who experienced maltreatment were more likely to see a faster increase in the amount of non-violent offending they engaged in. While these are two different components that describe increased offending frequency, they align with our hypothesis that increased

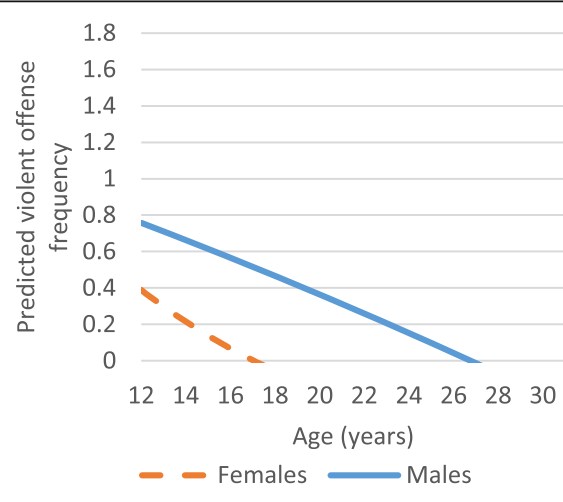

a

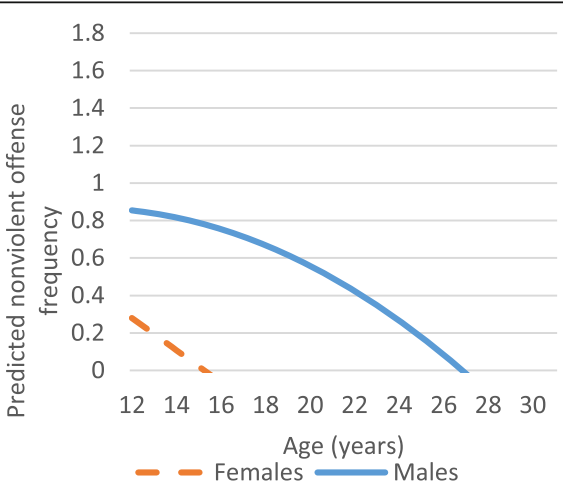

b

Solid Blue Line. Predicted violent offense frequency for males Dotted Red Line. Predicted violent offense frequency for females

Fig. 1 a Differences in predicted violent offense frequency by sex. b Differences in predicted nonviolent offense frequency by sex 


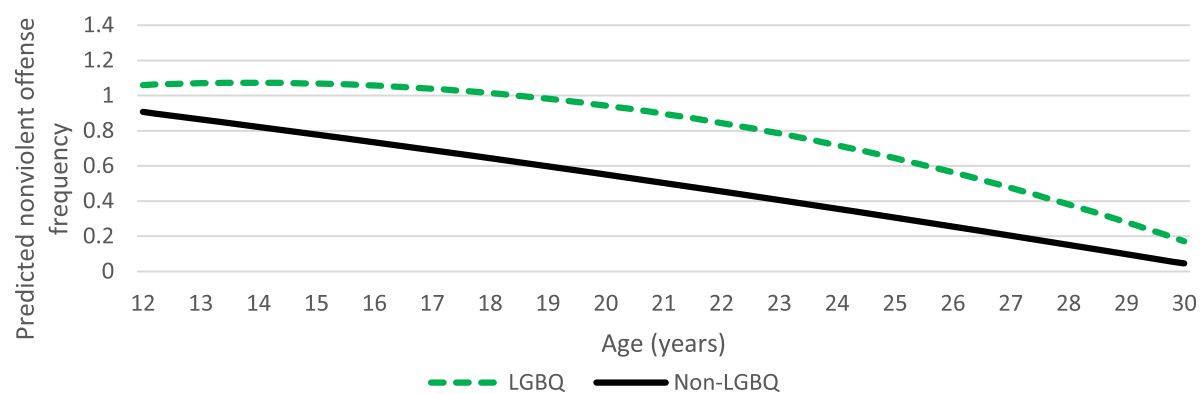

Solid Black line. Predicted nonviolent offense frequency for non-LGBQ respondents Dotted Green line. Predicted nonviolent offense frequency for LGBQ respondents

Fig. 2 Differences in predicted nonviolent offense frequency by sexual orientation

maltreatment experiences would be associated with both increased violent and non-violent offending behavior.

This paper also extends our understanding of the relationship between maltreatment and offending later in development. More frequently than exploring the relationship between childhood maltreatment and offending behaviors into adulthood (which has been explored minimally), papers explore the linkage between early childhood experiences of abuse, neglect, or trauma with long-term health outcomes or self-sufficiency [35-37]. Prior papers with delinquency outcomes have mostly focused their studies on adolescence or early adulthood (often age 21) $[21,32-34,38]$. The analyses here examined whether the decline in criminal behavior that we see in the administrative data extends through the 20's following maltreatment. Prior papers also tend to have outcomes at specific ages for the whole dataset (e.g., 15-19), and we build on this by having data from respondents at different ages to show the shape of trends from age 12 to 30 and allow for nonlinearity such that we can see that predicted offending frequency peaks at around age 16 .

To answer our second question, we explored differences by sex, race/ethnicity and sexual orientation. We did not find differences by race/ethnicity or sexual orientation. Our findings indicate that the link between maltreatment and later offending varies significantly by sex. Specifically, results showed differences in nonviolent offending between males and females, such that, among those who experienced maltreatment, the predicted nonviolent offense frequency was significantly higher for males compared to females. This was contrary to our hypothesis where we expected that even while males commit more offending behavior that the association with

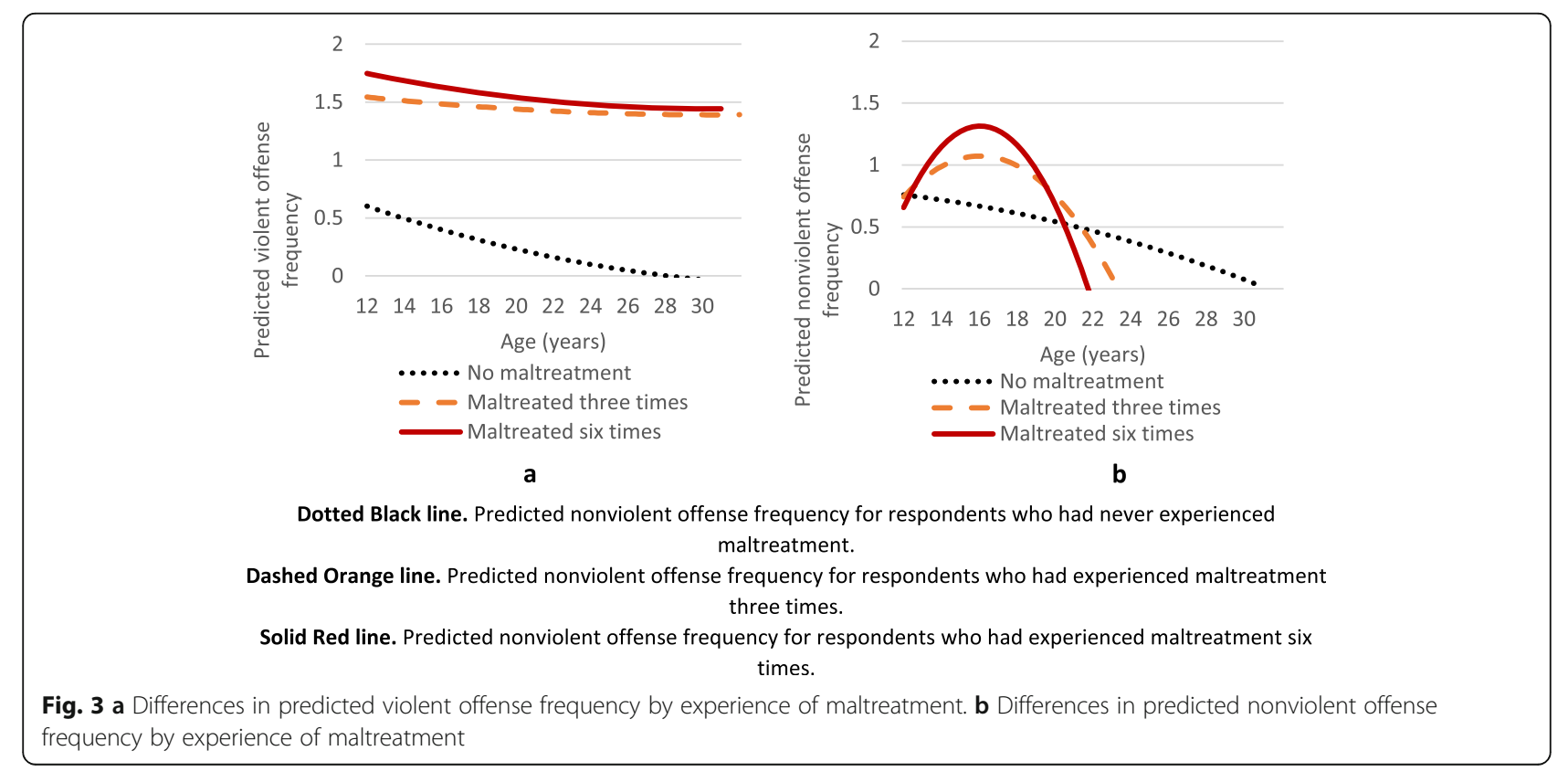




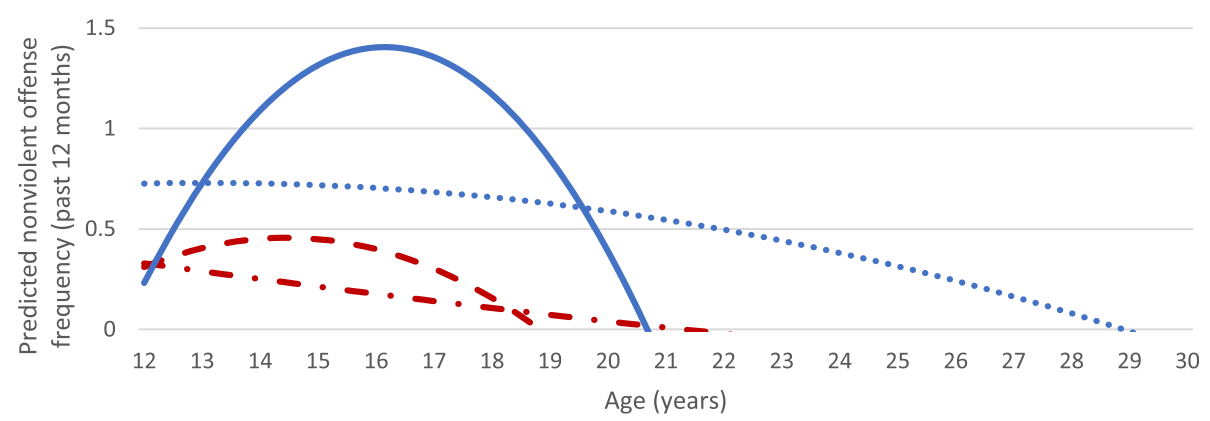

$$
\begin{aligned}
& \text { - P. Females, no maltreatment } \quad-\text { Females, maltreated } 6 \text { times } \\
& \text {.... Males, no maltreatment } \quad \text { Males, maltreated } 6 \text { times }
\end{aligned}
$$

Solid blue line. Males who had experienced maltreatment 6 or more times.

Dotted blue line. Males who had not experienced maltreatment.

Dashed red line. Females who had experienced maltreatment 6 or more times.

Dotted and dashed red line. Females who had not experienced maltreatment.

Fig. 4 Differences in predicted nonviolent offense frequency (past 12 months) by sex and maltreatment frequency

maltreatment would be stronger for females. Recent explorations of a similar question have found that the associations can vary across gender by type of maltreatment [39]. These findings have implications for the dialogue surrounding male-perpetrated offending because given recent research into trauma and externalizing behavior $[40,41]$, understanding males' experiences of maltreatment could help motivate the provision of needed therapeutic treatment or positive relationships that could reduce negative behaviors $[42,43]$. These findings may also shed light on the notions around gender and risky or offending behavior. The stronger relationship between maltreatment and nonviolent offense frequency for males indicates that the higher rate of offending among boys may not only be due to their higher proclivity for risk behavior but also due to an externalizing response to maltreatment. This finding is consistent with previous literature that demonstrates externalizing responses (e.g., delinquency) are more common for males, compared to the internalizing responses (e.g., depressive symptoms) that are more common for females [44, 45].

One important finding in this paper is that there are no differences seen for the relationship between maltreatment and either violent or nonviolent offending by either race/ethnicity or sexual orientation. Previous research with administrative samples has found a linkage by race [12] while other prospective studies also found no linkages between maltreatment and violent behavior by race [46]. We see this as positive in many ways. For instance, the lack of difference indicates that there is not one particular race or sexual orientation where maltreatment is associated with more subsequent offending, violent or nonviolent. More specifically, all youth - regardless of race/ethnicity or sexual orientation - negatively respond to maltreatment. These findings are not necessarily surprising given that it is likely that humans have universal biological and adaptive responses to maltreatment during childhood including how it affects their brains, emotions, and cognitive processes [47-50]. Rather, they should prompt us to think more broadly about trauma and children's behavior within the specific context in which they live, allowing us to respond more appropriately to their needs given their specific environmental exposures.

We also hypothesized that LGBQ youth may struggle with their mental health and exhibit more externalizing behaviors $[27,51,52]$. We did not see this in our results. (Note that while we did find small differences in nonviolent offending behavior by sexual orientation that these differences were found overall and were not based on different past experiences of maltreatment. Specifically, youth who identified as heterosexual or homosexual did not report different patterns of offending behavior following experiences of maltreatment than their straight peers. Therefore, while their behavior may be externalizing following other struggles, there do not appear to be differences in externalizing behavior following maltreatment by sexual orientation.) This may indicate either that non-heterosexual youth are doing better overall than we hypothesized and are more similar to their heterosexual peers, or that their struggles are more likely to be exhibited with internalizing symptoms rather than externalizing symptoms $[27,53,54]$.

Finally, we hypothesized that we may see differences across race due to different stressors and violence exposure. Despite finding no variation in delinquent or criminal behavior following experiences of maltreatment for adolescents and adults across race, there is substantial 
evidence for differential treatment after criminal or delinquent behavior occurs. Past studies find that both Black and Latino students are significantly more likely to receive a suspension in comparison to their white counterparts, a discrepancy that appears as early as preschool $[55,56]$. This trend continues through adolescence when Black and Latino individuals are more likely to have both contact with police as well as experience arrest and engagement in the juvenile justice system $[57,58]$. This is particularly true for boys. Our findings, coupled with past literature, reinforce the need to reexamine areas where inequalities in the trajectory from maltreatment to juvenile delinquency and offending persist so that we can create a more equitable juvenile and adult justice system.

There are several limitations to the analyses. Specifically, while the most recent round of Add Health data is brand new (2016-2018) [59] (we do not use this most recent wave), the respondents are now in their late 30s and early 40s, meaning that the experiences of maltreatment that we are analyzing happened some time ago. Fortunately, reports of childhood abuse and neglect have been declining in the last two decades [60]. This could mean that the relationships we see here may differ in a sample of youth who experienced maltreatment today; however, we also have seen delinquency decrease significantly over the same time period, bolstering the argument that these experiences and behaviors may be intertwined [43].

Additionally, exploring the linkages between specific types and frequencies of maltreatment with specific offending behaviors may be an important next step which we did not do here. Watts and Iratzoqui do look at this by gender in their new paper [39], which explored moderation by gender in how different types of abuse or neglect are associated with different types of delinquency. More research along this strain of questioning could shed light on whether certain types of maltreatment have a stronger relationship with certain types of offending and deserve more attention.

In addition to these challenges, the Cronbach's alphas for the offending frequency measures were as low as 0.5 at one of the waves, which indicate low internal consistency reliability of our outcome measures, particularly for nonviolent offending behavior at Wave I. Previous analyses of offending behavior using these data have constructed similar measures, so we used these measures to remain congruent with the broader field [28]. It makes sense the different behaviors measured by the non-violent offending scale would have lower internal consistency reliability than the violent offending scale as the behaviors in the former cover a wide range of behaviors (e.g., trespassing, theft, and injection drug use). By comparison, the behaviors measured in the violent offending scale seem more conceptually congruent as they all involve violent behaviors. Finally, while we mentioned above that there are pros and cons to self-report data, some research indicates that self-reported retrospective data is more likely to overestimate associations with self-reported outcomes. As our outcomes are self-reported, this is something to consider [61].

There are also strengths to these analyses. First, we are also to stratify by race/ethnicity and sexual orientation because of the sample size, and our data cover nearly 20 years of age. Second, the lack of variation from random effects in the intercept and slope indicate the sample results are well represented by the predicted plots. In other words, if we allowed the predicted lines to diverge to represent groups on one spectrum or the other of the association, the lines would be very close together. Building from these strengths in future research is essential as knowing particularly what experiences are urgently problematic is something that many parents, educators, healthcare providers, judges, and juvenile justice practitioners desperately want to know so that future delinquent behaviors can be prevented. Third, the Add Health study asked respondents how many times a respondent experienced maltreatment, rather than a simple "yes" or "no." Recent evidence indicates the frequency of maltreatment may matter more than the type of maltreatment, as types of maltreatment tend to co-occur $[56,62]$.

Additionally, while we discussed the weaknesses above of self-report data, it is important to note here that there are also strengths. Specifically, the rates of both maltreatment and offending behavior are higher in Add Health than in government reports. We likely capture experiences here that were not reported. This may indicate that Add Health was successful at giving adolescent's a sense of confidence and confidentiality in the survey and allowing them to feel safe self-reporting delinquent or criminal behaviors for which they did not get caught. It also may mean that a young person may have shared an experience they felt happened but under further investigation did not justify government reporting. More importantly though, both child welfare investigations and policing are patterned by socioeconomic status and race $[12,57,58,63]$. This is important because in this study we can capture youth who did not end up in the welfare or justice systems - who are overwhelmingly youth of color [64] - and therefore can create estimates for the associations for a broader range of youth. This strikes us as particularly important given that race is found to be a significant moderator in other administrative data studies [12] but not in some other prospective studies [46] suggesting that more exploration into the potential for bias here is important. We hope that the results here can be compared to studies of administrative data to better inform the field of 
potential strengths and biases to using both methods of data collection.

Finally, by using linear mixed effects models, we decreased the models' vulnerability to endogeneity. There are many potential factors that may be shared predictors of both maltreatment and delinquency, and our data source did not allow us to control for all of them. Other studies have used evaluations or natural experiments to find exogenous patterns but linear mixed effects models, by examining an individual's change over time, controls for those unobserved factors that are time invariant. This robust method allowed us to look at how these associations change when the frequency and types of maltreatment increased, as well as test for differences by sex, race/ethnicity, and sexual orientation.

\section{Conclusion}

Given our interesting findings as well as the strengths and limitations discussed above, further exploration into the relationship between childhood experiences of maltreatment and trauma are needed to better understand critical junctures and potential opportunities to support young people to overcome challenges. Specifically, better understanding the differences in experiences between males and females may be particularly important as it is becoming clearer that more females are becoming engaged in the juvenile justice system and that many males have also experienced maltreatment and trauma. In addition to contributing to literature surrounding these differences, our findings can inform others' (i.e., police officers, judges, teachers, etc.) views of externalizing behaviors, particularly in males but also for females as they engage with the juvenile justice system more. It is important for all professionals who work with young men - as well as their parents - to recognize that externalizing behavior can be a warning sign of underlying stressors that are impacting a young man's mental and physical well-being. Teaching adolescent boys and young men to understand and identify their stress responses could decrease their need for externalizing responses that can leave them vulnerable to continued trauma [65]. All youth deserve a system that addresses their hurt and supports them to grow into responsible, healthy adults.

\section{Supplementary information}

Supplementary information accompanies this paper at https://doi.org/10. 1186/s12889-019-7655-7.

Additional file 1: Table S1. Regression results from models two, three, and seven for violent offending (model titles described in columns below).
Additional file 2: Table S2. Regression results from models two, three, five, seven, and eight for nonviolent offending (model titles described in columns below).

Additional file 3: Table S3. Intraclass correlation for both violent and nonviolent offending models comparing baseline and analytic models.

\section{Abbreviations}

Add Health: National Longitudinal Study of Adolescent to Adult Health: ICC: Intraclass correlation coefficient; LGBQ: Lesbian, Gay, Bisexual, or Queer

\section{Acknowledgements}

The authors would like to thank Denise Herz, Carly Dierkhising, and Kristin Anderson Moore for incredibly helpful feedback and comments during the review of this manuscript.

\section{Authors' contributions}

$\mathrm{HL}$ helped AW design the study. HL also reviewed analyses, drafted the background, literature review, and discussion sections and reviewed the methods and results. AW led the analyses, drafted the methods and results sections, and reviewed the rest of the manuscript. HW conducted the initial literature review, outlined the introduction, and then edited the entire document for clarity. She also helped design all of the figures and Tables. TM ran most of the analyses with AW's help and guidance and then outlined the methods and results sections so that AW could quickly write it. All authors have read and approved of this final version of the manuscript.

\section{Funding}

The authors have no competing interests - financial or non-financial - to disclose and would like to acknowledge funding from the Office of Juvenile Justice and Delinquency Programming (OJJDP) at the United States Department of Justice. This project was supported by Grant \# 2016-MU-MU-0064 awarded by the OJJDP, Office of Justice Programs, U.S. Department of Justice. The opinions, findings, and conclusions or recommendations expressed in this publication are those of the author(s) and do not necessarily reflect those of the Department of Justice.

\section{Availability of data and materials}

This research uses data from Add Health, a program project directed by Kathleen Mullan Harris and designed by J. Richard Udry, Peter S. Bearman, and Kathleen Mullan Harris at the University of North Carolina at Chapel Hill, and funded by grant P01-HD31921 from the Eunice Kennedy Shriver National Institute of Child Health and Human Development, with cooperative funding from 23 other federal agencies and foundations. Special acknowledgment is due Ronald R. Rindfuss and Barbara Entwisle for assistance in the original design. Add Health has public-use data files. More information on how to obtain the Add Health data files is available on the Add Health website (http://www.cpc.unc.edu/addhealth). No direct support was received from grant P01-HD31921 for these analyses.

\section{Ethics approval and consent to participate}

Ethics review of the entire Add Health Study has been managed and conducted by the University of North Carolina (UNC) at Chapel Hill and their Institutional Review Board (IRB). This study and all relevant analyses were reviewed by Child Trends' IRB and deemed exempt. As all analyses here are secondary data analyses and UNC is responsible for the data collection ethics review, this research is considered exempt.

\section{Consent for publication}

There are no materials here that require consent for publication.

\section{Competing interests}

The authors declare that they have no competing interests.

\section{Author details}

'Child Trends, 7315 Wisconsin Ave, Suite 1200W, Bethesda, MD 20814, USA. 2Department of Population, Family, and Reproductive Health, Johns Hopkins Bloomberg School of Public Health, 615 N. Wolfe St, Baltimore, MD 21205, USA. ${ }^{3}$ Department of Maternal and Child Health, University of North Carolina Gillings School of Global Public Health, 135 Dauer Drive, Chapel Hill, NC 
27599, USA. ${ }^{4}$ Sociology Department, Graduate Student, Stanford University, 450 Serra Mall, Building 120, Room 160, Stanford, CA 94305-2047, USA.

\section{Received: 26 July 2018 Accepted: 20 September 2019 Published online: 12 November 2019}

\section{References}

1. Centers for Disease Control and Prevention. Child abuse and neglect: definitionshttps://www.cdc.gov/violenceprevention/childmaltreatment/ definitions.html. Published. Accessed 14 Feb 2018; 2016.

2. U.S. Department of Health and Human Services. Administration for children and families, administration on children, youth, and families, children's bureau. Child Maltreatment 2016. 2018; https://www.acf.hhs.gov/sites/ default/files/cb/cm2016.pdf.

3. U.S. Department of Health and Human Services. Administration for children and families, administration on children, youth, and families, children's bureau. Child Maltreatment 2015. 2017; https://www.acf.hhs.gov/sites/ default/files/cb/cm2015.pdf.

4. Archer G, Pinto Pereira S, Power C. Child maltreatment as a predictor of adult physical functioning in a prospective British birth cohort. BMJ Open. 2017. https://doi.org/10.1136/bmjopen-2017-017900.

5. Sacks R, Takemoto E, Andrea S. Childhood maltreatment and BMI trajectory: the mediating role of depression. Am J Prev Med. 2017;53(5):625-33.

6. Norman R, Byambaa M, De R, Butchart A, Scott J, Vos T. The long-term health consequences of child physical abuse, emotional abuse, and neglect: a systematic review and meta-analysis. PLoS Med. 2012:9(11):e1001349.

7. Hardner K, Wolf M, Rinfrette E. Examining the relationship between higher educational attainment, trauma symptoms, and internalizing behaviors in child sexual abuse survivors. Child Abuse Negl. 2017:86:375-83.

8. Snehal M, Pereira P, Li L, Power C. Child maltreatment and adult living standards at 50 years. Pediatrics. 2017;139(1):e20161595. https://doi.org/10. 1542/peds.2016-1595.

9. Mersky J, Topitzes J, Reynolds A. Unsafe at any age: linking childhood and adolescent maltreatment to delinquency and crime. J Res Crime Delinq. 2012; 49(2):295-318 http://doi.org.ezp.welch.jhmi.edu/10.1177/0022427811415284.

10. Finkelhor D, Turner H, Hamby S, Ormrod R. Polyvictimization: Children's exposure to multiple types of violence, crime, and abuse; 2011. https:// www.ncjrs.gov/pdffiles1/ojjdp/235504.pdf

11. Yonas MA, Lewis T, Hussey JM, et al. Perceptions of neighborhood collective efficacy moderate the impact of maltreatment on aggression. Child Maltreat. 2010:15(1):37-47. https://doi.org/10.1177/1077559509349445.

12. Goodkind S, Shook JJ, Kim KH, Pohlig RT, Herring DJ. From child welfare to juvenile justice: race, gender, and system experiences. Youth Violence Juvenile Justice. 2013;11(3):249-72. https://doi.org/10.1177/1541204012463409.

13. Mersky J, Reynolds A. Child maltreatment and violent delinquency: disentangling main effects and subgroup effects. Child Maltreat. 2007;12(3): 246-58. https://doi.org/10.1177/1077559507301842.

14. Bekbolatkyzy D, Yerenatovna D, Maratuly Y, Makhatovna G, Beaver K. Aging out of adolescent delinquency: results from a longitudinal sample of youth and young adults. J Crim Just. 2019;60:108-16. https://doi.org/10.1016/j. jcrimjus.2018.09.001

15. Farrell C, Zimmerman G. Is exposure to violence a persistent risk factor for offending across the life course? Examining the contemporaneous, acute, enduring, and long-term consequences of exposure to violence on property crime, violent offending, and substance use. J Res Crime Delinq. 2018;55(6):728-65. https://doi.org/10.1177/0022427818785207.

16. Maas C, Herrenkohl TI, Sousa C. Review of research on child maltreatment and violence in youth. Trauma Violence Abuse. 2008;9(1):56-67. https://doi. org/10.1177/1524838007311105.

17. Trickett PK, Negriff S, Ji J, Peckins M. Child maltreatment and adolescent development. J Res Adolesc. 2011;21(1):3-20. https://doi.org/10.1111/j.15327795.2010.00711.x

18. Yun I, Ball JD, Lim H. Disentangling the relationship between child maltreatment and violent delinquency: using a nationally representative sample. J Interpers Violence. 2011;26(1):88-110. https://doi.org/10.1177/ 0886260510362886

19. Currie J, Tekin E. Understanding the cycle: childhood maltreatment and future crime. J Hum Resour. 2012:47(2):509-49. https://doi.org/10.1353/jhr.2012.0017.

20. Godinet M, Li F, Berg T. Early childhood maltreatment and trajectories of behavioral problems: exploring gender and racial differences. Child Abuse Negl. 2014;38:546. https://doi.org/10.1016/j.chiabu.2013.07.018.
21. Lansford JE, Miller-Johnson S, Berlin LJ, Dodge KA, Bates JE, Pettit GS. Early physical abuse and later violent delinquency: a prospective longitudinal study. Child Maltreat. 2007;12(3):233-45. https://doi.org/10.1177/ 1077559507301841

22. Graziano JN, Wagner EF. Trauma among lesbians and bisexual girls in the juvenile justice system. Traumatology (Tallahass Fla). 2011;17(2):45-55. https://doi.org/10.1177/1534765610391817.

23. Hatcher S. Exploring the impact of racial and ethnic differences in the emotional and behavioral responses of maltreated youth: implications for culturally competent services. Child Youth Serv Rev. 2009;31(9):1042-8. https://doi.org/10.1016/j.childyouth.2009.05.005.

24. Shaffer A, Huston L, Egeland B. Identification of child maltreatment using prospective and self-report methodologies: a comparison of maltreatment incidence and relation to later psychopathology. Child Abuse Negl. 2008; 32(7):682-92.

25. Harris K. The add health study: design and accomplishmentshttp://www. cpc.unc.edu/projects/addhealth/data/guides/DesignPaperWIIV.pdf. Accessed 22 Mar 2016. Published; 2013.

26. Font SA, Berger LM. Child maltreatment and children's developmental trajectories in early to middle childhood. Child Dev. 2015;86(2):536-56. https://doi.org/10.1111/cdev.12322

27. Beaver K, Connolly E, Schwartz J, Boutwell B, Barnes J, Nedelec J. Sexual orientation and involvement in nonviolent and violent delinquent behaviors: findings from the national longitudinal study of adolescent to adult health. Arch Sex Behav. 2016;45(7):1759-69. https://doi.org/10.1007/s10508-016-0717-3.

28. Guo G, Roettger ME, Shih JC. Contributions of the DAT1 and DRD2 genes to serious and violent delinquency among adolescents and young adults. Hum Genet. 2007. https://doi.org/10.1007/s00439-006-0244-8.

29. Crooks CV, Scott KL, Wolfe DA, Chiodo D, Killip S. Understanding the link between childhood maltreatment and violent delinquency: what do schools have to add? Child Maltreat. 2007. https://doi.org/10.1177/ 1077559507301843.

30. Thornberry TP, Henry KL, Smith CA, Ireland TO, Greenman SJ, Lee RD. Breaking the cycle of maltreatment: the role of safe, stable, and nurturing relationships. J Adolesc Health. 2013. https://doi.org/10.1016/j.jadohealth.2013.04.019.

31. Bender K. The mediating effect of school engagement in the relationship between youth maltreatment and juvenile delinquency. Child Sch. 2012. https://doi.org/10.1093/cs/cdr001.

32. DeHart D, Moran R. Poly-victimization among girls in the justice system: trajectories of risk and associations to juvenile offending. Violence Against Women. 2015;21(3):291-312.

33. Ryan J, Hernandez P, Herz D. Developmental trajectories of offending for male adolescents leaving foster care. Soc Work Res. 2007;31(2):83-93.

34. Stewart A, Livingston M, Dennison S. Transitions and turning points: examining the links between child maltreatment and juvenile offending Child Abuse Negl. 2008;32(1):51-66

35. Felitti VJ, Anda RF, Nordenberg D, et al. Relationship of childhood abuse and household dysfunction to many of the leading causes of death in adults: the adverse childhood experiences (ACE) study. Am J Prev Med. 1998;14(4):245-58. https://doi.org/10.1016/S0749-3797(98)00017-8.

36. Mersky J, Topitzes J, Reynolds A. Impacts of adverse childhood experiences on health, mental health, and substance use in early adulthood: a cohort study of an urban, minority sample in the U.S. Child Abuse Negl. 2013; 37(11):917-25. https://doi.org/10.1016/j.chiabu.2013.07.011.

37. Anda R, Fleisher $V$, Felitti $\vee$, et al. Childhood abuse, household dysfunction, and indicators of impaired adult worker performance. Perm J. 2004;8(1):30-8.

38. Silverman A, Reinherz H, Giaconia R. The long-term sequelae of child and adolescent abuse: a longitudinal community study. Child Abuse Negl. 1996; 20(8):709-23.

39. Watts SJ, Iratzoqui A. Gender, child maltreatment, and delinquency. Vict Offenders. 2019;14(2):165-82. https://doi.org/10.1080/15564886.2018.1557091.

40. Rholes S, Paetzold R, Kohn J. Disorganized attachment mediates the link from early trauma to externalizing behavior in adult relationships. Personal Individ Differ. 2016;90:61-5. https://doi.org/10.1016/j.paid.2015.10.043.

41. Cohen J, Mannarino A, Lyengar S. Community treatment of posttraumatic stress disorder for children exposed to intimate partner violence: a randomized controlled trial. Arch Pediatr Adolesc Med. 2011;165(1):16-21. https://doi.org/10.1001/archpediatrics.2010.247.

42. Folger SF, Wright MOD. Altering risk following child maltreatment: family and friend support as protective factors. J Fam Violence. 2013;28(4):325-37. https://doi.org/10.1007/s10896-013-9510-4. 
43. Office of Juvenile Justice and Delinquency Prevention. Juvenile arrest rate Trends. OJJDP statistical briefing book. Accessed 5 Mar 2018. https://www. ojjdp.gov/ojstatbb/crime/JAR_Display.asp?ID=qa05230. Published; 2017.

44. Lewis T, McElroy E, Harlaar N, Runyan D. Does the impact of child sexual abuse differ from maltreated but non-sexually abused children? A prospective examination of the impact of child sexual abuse on internalizing and externalizing behavior problems. Child Abuse Negl. 2016 https://doi.org/10.1016/j.chiabu.2015.11.016.

45. Nolen-Hoeksema S. Emotion regulation and psychopathology: the role of gender. Annu Rev Clin Psychol. 2012:8:161-87. https://doi.org/10.1146/ annurev-clinpsy-032511-143109.

46. Lee C, Cronley C, White H, Mun E, Stouthamer-Loeber M, Loeber R. Racial differences in the consequences of childhood maltreatment for adolescent and young adult depression, heavy drinking, and violence. J Adolesc Health. 2012;50(5):443-9. https://doi.org/10.1016/j.jadohealth.2011.09.014.

47. Child Welfare Information Gateway. Understanding the effects of maltreatment on brain development. Washington, DC: Children's Bureau; 2015.

48. O'Mahen H, Karl A, Moberly N, Fedock G. The association between childhood maltreatment and emotion regulation: two different mechanisms contributing to depression? J Affect Disord. 2015;174:287-95. https://doi. org/10.1016/j.jad.2014.11.028.

49. Divr Y, Ford J, Hill M, Frazier J. Childhood maltreatment, emotional dysregulation, and psychiatric comorbidities. Harv Rev Psychiatry. 2014;22(3): 149-61. https://doi.org/10.1097/HRP.0000000000000014.

50. Gould F, Clarke J, Heim C, Harvey P, Majer M, Nemeroff C. The effects of child abuse and neglect on cognitive functioning in adulthood. J Psychiatr Res. 2012:46(4):500-6. https://doi.org/10.1016/j.jpsychires.2012.01.005.

51. Everett B. Sexual orientation identity change and depressive symptoms: a longitudinal analysis. J Health Soc Behav. 2015;56(1):37-58.

52. Goldbach J, Tanner-Smith E, Bagwell M, Dunlap S. Minority stress and substance use in sexual minority adolescents: a meta-analysis. Prev Sci. 2013;15(3):350-63.

53. Hatzenbuehler M, McLaughlin K, Nolen-Hoeksema S. Emotion regulation and internalizing symptoms in a longitudinal study of sexual minority and heterosexual adolescents. J Child Psychol Psychiatry. 2008;49(12):1270-8. https://doi.org/10.1111/j.1469-7610.2008.01924.x

54. Caplan Z. The problem with square pegs: sexual orientation concordance as a predictor of depressive symptoms. Soc Ment Health. 2017;7(2):105-20.

55. Loveless T. The 2017 Brown Center report on American education: how well are American students learning? Brookings Inst. 2017;3(6):1-40. Retrieved from here: https://www.brookings.edu/wp-content/uploads/2016/03/BrownCenter-Report-2016.pdf.

56. U.S. Department of Education Office for Civil Rights. Data snapshot: early childhood education. Civ Rights Data Collect. 2014;(2). Retrieved from here: https://www2.ed.gov/about/offices/list/ocr/docs/crdc-early-learning-snapshot.pdf.

57. Crutchfield RD, Skinner ML, Haggerty KP, McGlynn A, Catalano RF. Racial disparity in police contacts. Race Justice. 2012;2(3). https://doi.org/10.1177/ 2153368712448063.

58. Sickmund M, Puzzanchera C. Juvenile offenders and victims: 2014 National Report. Pittsburgh: National Center on Juvenile Justice and OJJDP; 2014. Retrieved from here: https://www.ojjdp.gov/ojstatbb/nr2014/downloads/ NR2014.pdf.

59. Carolina Population Center, Eunice Kennedy Shriver National Institute of Child Health and Human Development. Wave V. the National Longitudinal Study of adolescent to adult healthhttps://www.cpc.unc.edu/projects/ addhealth/design/wave-v-1. Accessed 11 June 2019 Published; 2019.

60. Trends C. Databank indicator: child maltreatment. Bethesda; 2016. Retrieved from here: https://www.childtrends.org/indicators/child-maltreatment.

61. Reuben A, Moffitt T, Belsky D, et al. Lest we forget: comparing retrospective and prospective assessments of adverse childhood experiences in the prediction of adult health. J Child Psychol Psychiatry Allied Discip. 2016; 57(10):1103-12. https://doi.org/10.1111/jcpp.12621.

62. Bronfenbrenner $U$. The ecology of human development: experiments by nature and design. Cambridge: Harvard University Press; 1981.

63. Widom CS, Czaja S, Wilson HW, Allwood M, Chauhan P. Do the long-term consequences of neglect differ for children of different races and ethnic backgrounds? Child Maltreat. 2013;18(1):42-55. https://doi.org/10.1177/ 1077559512460728.

64. HerrenkohI TI, Tajima EA, Whitney SD, Huang B. Protection against antisocial behavior in children exposed to physically abusive discipline. J Adolesc Health. 2005. https://doi.org/10.1016/j.jadohealth.2003.09.025.
65. Dierkhising CB, Ko S, Goldman JH. Trauma-informed juvenile justice roundtable: current issues and new directions in creating trauma-informed juvenile justice systems. Los Angeles; 2013. http://www.taysf.org/wpcontent/uploads/2014/08/jj_trauma_brief_introduction_final.pdf

\section{Publisher's Note}

Springer Nature remains neutral with regard to jurisdictional claims in published maps and institutional affiliations.
Ready to submit your research? Choose BMC and benefit from:

- fast, convenient online submission

- thorough peer review by experienced researchers in your field

- rapid publication on acceptance

- support for research data, including large and complex data types

- gold Open Access which fosters wider collaboration and increased citations

- maximum visibility for your research: over $100 \mathrm{M}$ website views per year

At BMC, research is always in progress.

Learn more biomedcentral.com/submissions 